\section{Commentary: A directed look at socioeconomic position and length of stay: Can we break the cycle?}

\author{
Tara Karamlou, MD, MSc
}

\begin{abstract}
Spigel and colleagues, ${ }^{1}$ in this issue of the Journal, investigated an increasingly important question for congenital heart surgeons, and by extension, the field of congenital heart disease. These authors studied the relationship between hospital length of stay (LOS) following Norwood palliation and socioeconomic position (SEP) at their center. The purpose for the study was to better understand whether the use of LOS as a quality indicator within the Society of Thoracic Surgeons' Congenital Heart Surgery Database (which has been proposed by Pasquali and colleagues ${ }^{2}$ ), would negatively bias such results against centers with a high prevalence of socioeconomically fragile patients.

The authors included 98 patients discharged alive between 2008 and 2018 following Norwood palliation year period at their quaternary center. Patients who died or underwent transplantation $(\mathrm{N}=27 ; 17 \%)$, and those who remained inhospital during the interstage period $(\mathrm{N}=40 ; 24 \%)$, were excluded. Median length of stay was 37 days, with an interquartile range of 25 to 72 days. The vast majority of patients were White $(54 \%)$ or Hispanic (39\%), and most had private insurance and were children of US citizens. The authors used a metric known as the area deprivation index (ADI), ${ }^{3}$ which integrates 17 weighted measures of SEP. Median ADI in this study was 54 (range, 25-87), with greater ADI reflective of worse SEP. Using acyclic graphs and binomial modeling, Spigel and colleagues ${ }^{1}$ found that every $10 \%$ ADI increase resulted in a $4 \%$ increase in LOS.
\end{abstract}

\footnotetext{
From Cleveland Clinic Children's and the Heart, Vascular, and Thoracic Institute, Cleveland, Ohio.

Disclosures: The author reported no conflicts of interest.

The Journal policy requires editors and reviewers to disclose conflicts of interest and to decline handling or reviewing manuscripts for which they may have a conflict of interest. The editors and reviewers of this article have no conflicts of interest.

Received for publication Oct 27, 2021; revisions received Oct 27, 2021; accepted for publication Oct 27, 2021; available ahead of print Oct 29, 2021.

Address for reprints: Tara Karamlou, MD, MSc, Cleveland Clinic Children's and the Heart, Vascular, and Thoracic Institute, 9500 Euclid Ave, M41-022A, Cleveland, OH 44195 (E-mail: karamt@ccf.org).

J Thorac Cardiovasc Surg 2022;163:1612-3

0022-5223/ $\$ 36.00$

Copyright (c) 2021 by The American Association for Thoracic Surgery

https://doi.org/10.1016/j.jtcvs.2021.10.044
}

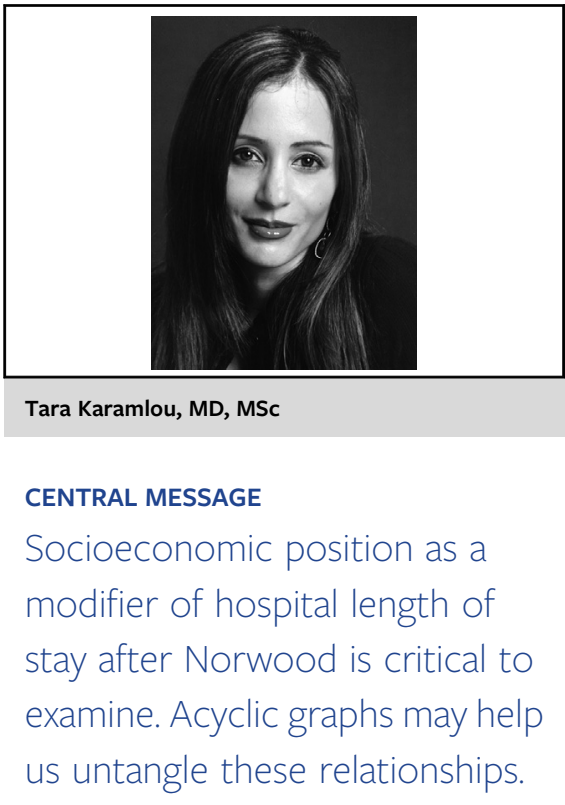

This is a very well-written paper, and the authors have used very appropriate yet underused methods, specifically acyclic graphs, to tease out the relationships between SEP and LOS. The authors briefly introduce the concept of acyclic graphs, but perhaps a bit more information would help our surgical community better digest the results. Acyclic graphs represent a visual tool to organize concepts relevant to many clinical scenarios-exposure, outcome, causation, confounding, and bias. ${ }^{4}$ These graphs can also be used to anticipate potential threats and validity in randomized controlled clinical trials, thereby improving a priori trial design. Acyclic graphs should generally be qualified by the term "directed," meaning that the paths cannot contain feedback loops in which one variable in the path leads back to itself. In simpler terms, directionality mitigates causal associations and multicollinearity among variables-a major limitation to even the most robust statistical models. Spigel and colleagues ${ }^{1}$ have exploited this benefit to untangle the highly related factors that contribute to the construct, SEP.

Despite their thoughtful methodologic approach, the present study still incompletely addresses the question of "how does SEP impact LOS?" Patients who died, or those who underwent transplantation were not included. Similarly, patients who remained in-hospital between stage 1 and 2 were excluded. Although the authors' rationale for their exclusion criteria have face validity, if we were to consider the metric, LOS, as a quality metric, it is critical to propose (or at least postulate) approaches to allow incorporation of patients in 
whom an adverse outcome occurred. In other words, how can we reconcile the paradox that hospitals with mortality or transplant prevalence would appear better than those in whom patients experienced complications, yet survived to discharge? Failure to rescue metrics may represent one such strategy, but of course calibration of complications and identification of the first "sentinel event" that then cascades to other downstream complications is challenging without time-date stamping for perioperative complications.

Generalizability of the results is another limitation of the present study, given the preponderance of White patients. Some elaboration of how the SEP and racial/ethnic makeup of the study population compares to the general Texas population and to the national landscape of congenital heart surgery is warranted. The parental home address as the home address may also introduce bias into the study, as young parents of low SEP particularly may not live with their parents at the time of inclusion in the study. This is especially important for those aged 18 to 26 years, who still may be covered under the insurance policies held by their parents.
Finally, the lack of relationship between the distance traveled and LOS, particularly because private insurance was associated with greater distance traveled, is particularly interesting. Our group ${ }^{5}$ has explored the argument "access versus excess" in the lens of potential regionalization of congenital heart surgery care delivery. The results reported by Spigel and colleagues ${ }^{1}$ suggest that disparities in access to high-quality care for Norwood palliation may be a very real issue that will not be easy to resolve.

\section{References}

1. Spigel ZA, Kalustian AB, Zink JA, Binsalamah ZM, Caldarone CA. Low parenta socioeconomic position results in longer post-Norwood length of stay. J Thorac Cardiovasc Surg. 2022;163:1604-11.e1.

2. Pasquali SK, Shahian DM, O'Brien SM, Jacobs ML, Gaynor JW, Romano JC et al. Development of a congenital heart surgery composite quality metric: part 1-conceptual framework. Ann Thorac Surg. 2019;107:583-9.

3. Neighborhood Atlas. Accessed October 23, 2021. https://www.neighborhoodatlas medicine.wisc.edu/

4. Williams TC, Bach CC, Matthiesen NB, Henriksen TB, Gagliardi L. Directed acyclic graphs: a tool for causal studies in paediatrics. Pediatr Res. 2018;84: 487-93.

5. Karamlou T, Johnston DR, Backer CL, Roselli EE, Welke KF, Caldarone CA, et al. Access or excess? Examining the argument for regionalized cardiac care. J Thorac Cardiovasc Surg. 2020;160:813-9.
See Article page 1604

\section{Commentary: SEParating out the details in quality metrics}

\author{
Megan Schultz, MD, MS, and Ming-Sing Si, MD
}

Appropriate quality metrics for congenital cardiac surgery have been keenly debated during the past several years. Recently, a composite metric, including length of stay, was proposed for the Congenital Heart Surgery Database. ${ }^{1}$ Because length of stay may be influenced by

\footnotetext{
From the Division of Cardiac Surgery, Department of Surgery, David Geffen School of Medicine at UCLA, Los Angeles, Calif.

Disclosures: The authors reported no conflicts of interest.

The Journal policy requires editors and reviewers to disclose conflicts of interest and to decline handling or reviewing manuscripts for which they may have a conflict of interest. The editors and reviewers of this article have no conflicts of interest.

Received for publication Oct 29, 2021; revisions received Oct 29, 2021; accepted for publication Oct 29, 2021; available ahead of print Nov 3, 2021.

Address for reprints: Ming-Sing Si, MD, UCLA Division of Cardiac Surgery, Department of Surgery, David Geffen School of Medicine at UCLA, 62-246 CHS, 10833 Le Conte Ave, Los Angeles, CA 90095-1741 (E-mail: msi@mednet.ucla.edu).

J Thorac Cardiovasc Surg 2022;163:1613-4

$0022-5223 / \$ 36.00$

Copyright (C) 2021 by The American Association for Thoracic Surgery

https://doi.org/10.1016/j.jtcvs.2021.10.051
}

Check for updates

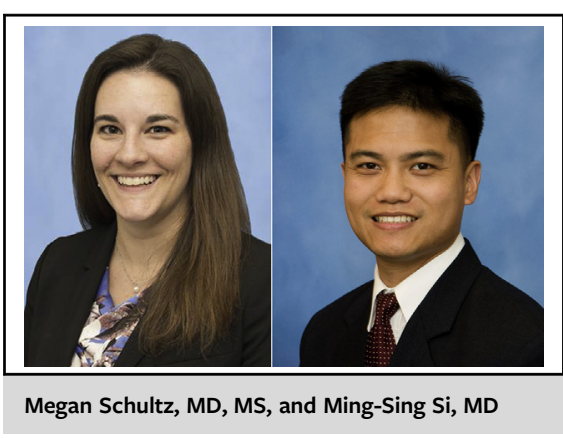

CENTRAL MESSAGE

Parental socioeconomic position influences length of stay after the

Norwood procedure and thus

may influence quality metrics

used to evaluate quality of care.

factors that are not related to treatment, including socioeconomic status, the validity of this composite metric may be lessened.

Spigel and colleagues ${ }^{2}$ examined how length of stay after a Norwood procedure may be related to parental 